\title{
Spatial and long-term temporal assessment of organic hazardous air pollutants and their comparative health risks
}

\author{
K. H. Kim ${ }^{1} \cdot$ H.-H. Chun ${ }^{2}$ W. K. Jo ${ }^{1}$
}

Received: 17 January 2014/Revised: 1 February 2015/Accepted: 21 April 2015/Published online: 5 May 2015

(C) Islamic Azad University (IAU) 2015

\begin{abstract}
This study investigated the spatial and longterm temporal characteristics of 13 selected organic hazardous air pollutants and the health risks associated with inhalation exposure over a recent 6-year period. Regional types selected for this study included a residential-commercial complex, traffic junction, petrochemical industry, iron and metal industry, and background areas in Korea. Toluene was generally the most abundant pollutants in all areas. The petrochemical industrial area had the highest median concentrations of six pollutants (benzene, ethyl benzene, $o$-xylene, $m, p$-xylene, styrene, and chloroform), followed by the residential-commercial complex, traffic junction, iron and metal industry, and background area. The residential-commercial complex and traffic junction areas showed the highest and second highest toluene concentrations, respectively. Two pollutants (1,1-dichloroethane and 1,3-butadiene) were present in similar concentrations among the five areas. In addition, the temporal trends in the annual mean concentrations exhibited unpredictable behavior depending on both the area and the type of pollutants. At the residential-commercial complex and traffic junction areas, six aromatic compounds showed significant correlations among themselves. In most cases, three important meteorological parameters (relative humidity, temperature, and wind speed) were not significantly correlated with ambient pollutant concentrations. Benzene
\end{abstract}

W. K. Jo

wkjo@knu.ac.kr

1 Department of Environmental Engineering, Kyungpook National University, Daegu 702-701, Korea

2 Department of Naval Architecture and Ocean Engineering, Pusan National University, 63 Jangjeon-dong, Geumjeonggu, Busan 609-735, Korea was the only pollutant that exceeded the cancer risk levels of $1 \times 10^{-6}$, and this excess was only observed at certain areas.

Keywords Residential-commercial - Traffic junction . Petrochemical · Iron and metal · Long-term characteristics . Meteorological parameters

\section{Introduction}

Hazardous air pollutants (HAPs) are airborne toxins that have the potential to increase population health risks of cancer and reproductive, immunological, developmental, and neurological disorders (USEPA 2010). HAPs and other volatile organic compounds can also easily photochemically react with hydroxyl radicals and other oxidants in the atmosphere to produce secondary toxic oxidants such as ozone and aldehydes and secondary organic aerosols (Stroud et al. 2008). These characteristics of HAPs necessitate that their atmospheric concentrations be managed. In the USA, the federal Clean Air Act Amendments of 1990 authorized the United States Environmental Protection Agency (USEPA) to regulate emissions of 188 HAPs. Similarly, there has been growing public concern regarding HAPs in Korea, particularly in urban areas, which has led the Korean Ministry of Environment (KME) to regulate their emissions (KME 2008; Shin and Yang 2010). Initially, 16 HAPs were regulated by the KME in 1978, and 48 HAPs are currently regulated (Shin and Yang 2010). Developing effective regulation and control strategies to reduce health risks associated with population exposure to HAPs requires the identification and quantification of individual HAPs. Accordingly, the KME developed a monitoring program for 13 volatile organic compounds 
(VOCs) and seven polycyclic aromatic hydrocarbons. These compounds have been monitored monthly in several Korean urban and suburban areas by the KME since 1995 . Even though the increased national concern regarding air pollutants in Korea has led to significant investment in pollution control measures, the effects of these measures on atmospheric air quality have not yet been properly evaluated (Yoo et al. 2008).

Several risk analysis studies essential to the establishment of HAPs regulation strategies have been conducted based on data obtained during monitoring of ambient HAPs (Touma et al. 2006; McCarthy et al. 2009). Different areas can exhibit different distributions of ambient HAPs, resulting in different health risks (Khoder 2007; Hoque et al. 2008). However, even though data describing atmospheric HAP concentrations in areas with different characteristics in Korea are available, they have not yet been properly incorporated to provide valuable information for assessment of health risks associated with population exposure. Moreover, the HAPs emission strength of many anthropogenic sources can change over long-term periods, which is reflected in the concentrations of atmospheric HAPs (Blanchard et al. 2010).

Therefore, the present study was conducted to investigate the spatial and long-term temporal characteristics of 13 selected organic HAPs and the health risks associated with inhalation exposure over a recent 6 -year period. Regional types selected for this study included a residentialcommercial complex, traffic junction, petrochemical industry, iron and metal industry, and background areas. The target HAPs are primarily released into urban atmospheres from anthropogenic sources such as motor vehicle exhaust and other combustion processes utilizing fossil fuels, petroleum storage and distribution, solvent usage, and other industrial processes (Badol et al. 2008). These compounds have acute and/or chronic adverse health effects (USEPA 2010), as well as the potential to form secondary toxic air pollutants via photochemical reactions with $\mathrm{OH}$ radicals and other oxidants (Carter and Seinfeld 2012). Cancer risks associated with chronic inhalation exposure were estimated using unit risks (URs), while hazard quotients (HQs) for acute inhalation exposure were calculated using reference concentrations (RfCs) or reference exposure levels (RELs).

\section{Materials and methods}

\section{Study protocol}

Five areas with different characteristics that were selected for investigation of selected organic HAPs from 2006 to 2011 are presented in Fig. 1. The survey areas were as follows: RCS, residential-commercial complex area at
Seoul, which is the capital of Korea and has a population of ca. 9.63 million and an area of $605 \mathrm{~km}^{2}$; TJS, traffic junction area in Seoul; PIU, petrochemical industries-concentrated area in Ulsan, which has a population of ca. 1.07 million and an area of $1059 \mathrm{~km}^{2}$; IMP, iron and metal industries-concentrated area at Pohang, which has a population of ca. 0.51 million and an area of $1128 \mathrm{~km}^{2}$; and BAP, background area at suburban Padolee, Chungnam, which has a population of ca. 0.04 million and an area of $505 \mathrm{~km}^{2}$. At each area, the 24-h resolution VOC concentrations were determined by averaging the concentrations of eight 3-h VOC samples (2-h sampling and 1-h analysis) collected at flow rates of $10-40 \mathrm{ml} \mathrm{min}{ }^{-1}$. One sample every month was collected from each monitoring station. These measurements were taken according to the Korean standard method for VOC measurements. Ambient VOC sampling was conducted on the roofs of 3- to 5-storey buildings by drawing air through a stainless steel trap with a $1 / 4$ in. outside diameter and length of $10 \mathrm{~cm}$ that contained Tenax TA. A coupled on-site thermal desorption system (Unity/Air Server, Markes) and GC/Deans switch/dualflame ionization detector system (Varian 3800) with a capillary column (Restek RTX-1, $60 \mathrm{~m} \times 0.32 \mathrm{~mm} \times 3 \mu \mathrm{m}$ ) or a coupled TDS (Ultra TD Auto Sampler, Markes) and GC/mass selective detector system (Varian Saturn 2000) were utilized to measure ambient target VOCs. The target compounds were selected based on their prevalence in ambient air and toxic effects. The target compounds included benzene (BZ), toluene (TL), ethyl benzene (EB), o-xylene (OX), $m, p$-xylene (MPX), styrene (ST), chloroform (CF), methyl chloroform (MCF), trichloroethylene (TCE), perchloroethylene (PCE), 1,1dichloroethane (11DCE), carbon tetrachloride (CT), and 1,3-butadiene (13BT). For quality control, gas-phase calibration mixtures of the target compounds with the concentration range of $0.01-100 \mathrm{ppb}$ and field as well as laboratory blanks (Tenax TA traps without injecting calibration mixtures) were introduced to the analytical system in the same way as for ambient air samples. Once the data were quality assured, the information was transferred to the Air Quality Management Bureau of the KME. We chose to begin our study with data from 2006 because the data have been quality assured since this year. VOC concentrations of measurements below the method detection limits (MDLs) were set to half of the MDLs of the respective VOCs for the conservative calculations of statistical values using SAS software (Su et al. 2013). The MDLs of the target compounds ranged from 0.01 to $0.08 \mathrm{ppb}$.

\section{Health risk analysis}

The target VOCs were classified into two sub-categories based on whether they were carcinogenic or non- 

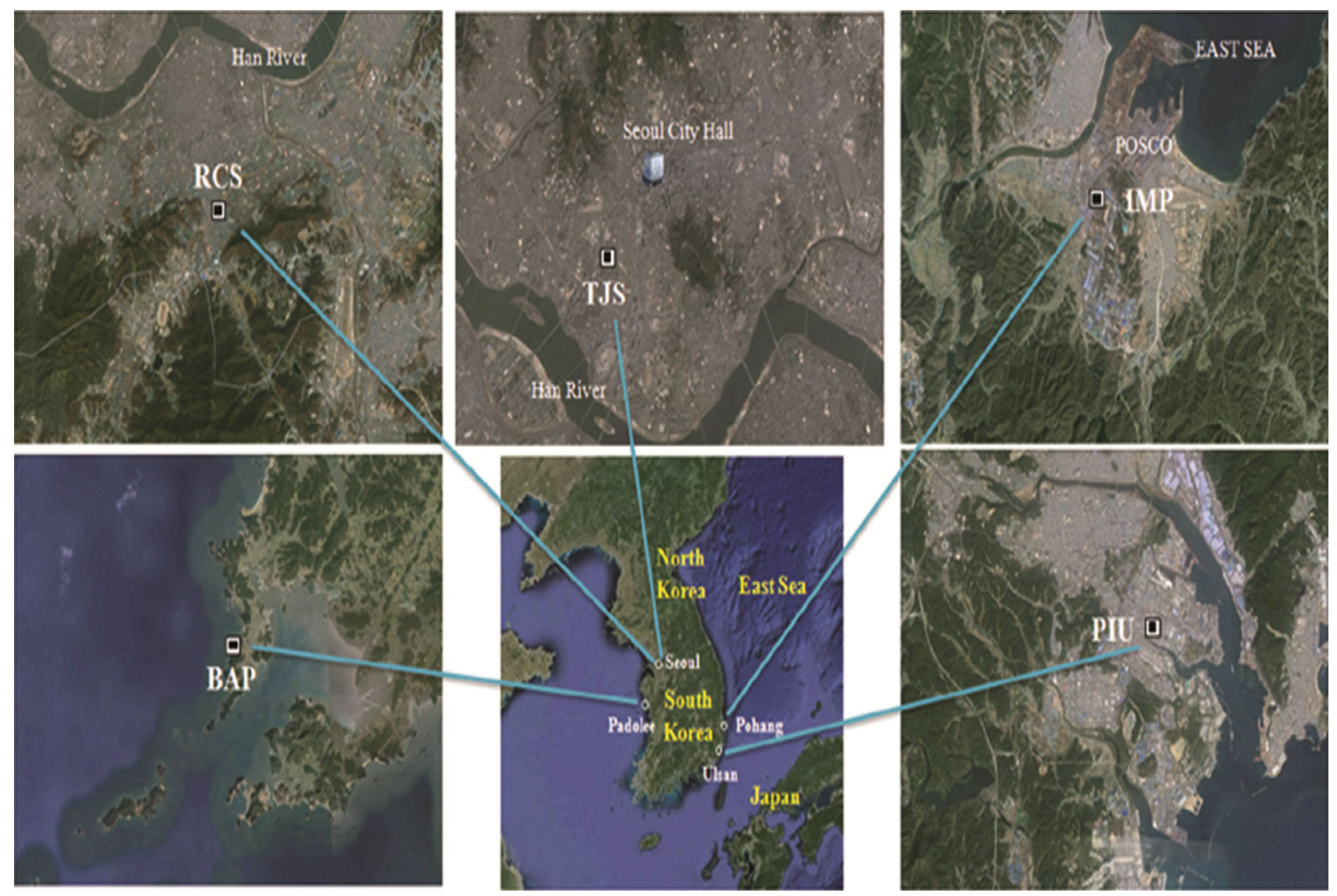

Fig. 1 Map of monitoring areas. RCS residential-commercial complex at Seoul, TJS traffic junction area at Seoul, PIU petrochemical industriesconcentrated area at Ulsan, IMP iron and metal industries-concentrated area at Pohang, BAP background area at Padolee, Chungnam

carcinogenic to estimate their health risks. The expected excess cancer risks $\left(\mathrm{R}_{\mathrm{c}} \mathrm{s}\right)$ and non-carcinogenic health risks as HQs were estimated using published URs and inhalation RfCs or RELs, respectively, as follows (Tam and Neumann 2004; Barregard et al. 2009):

$\left[\mathrm{R}_{\mathrm{c}}=\mathrm{C}_{\mathrm{VOC}} \times \mathrm{UR}\right]$

$\left[\mathrm{HQ}=\mathrm{C}_{\mathrm{VOC}} / \mathrm{RfC}\right.$ or REL $]$

where $\mathrm{C}_{\mathrm{VOC}}$ is the measured median concentration; UR is the inhalation unit risk, which is the upper-bound excess lifetime cancer risk calculated to result from exposure to specified VOCs at a concentration of $1 \mathrm{ppb}$; RfC is the maximum acceptable inhalation concentration of a specified VOC set by the USEPA; and REL is the occupational exposure limit recommended by the United States NIOSH and OSHA for adoption as a permissible exposure limit of a specified VOC. Four VOCs (BZ, CL, CT, and 13BT) had both unit risk values and RfC or REL values available, while only RfC or REL values were available for the nine remaining VOCs (TL, EB, OX, MPX, ST, MCF, TCE, PCE, and 11DCE) (USEPA 2010).

\section{Results and discussion}

\section{Characteristics of ambient HAPs by area}

The characteristics of long-term ambient organic HAP concentrations monitored at five different areas were investigated. Figure 2 summarizes the 24-h average concentrations of 13 selected HAPs obtained from five monitoring stations (RCS, TJS, PIU, IMP, and BAP) from 2006 to 2011 . The mean values were generally higher than the median values, indicating that HAP concentrations were not normally distributed. Therefore, a normality test (Shapiro-Wilk statistical test) was conducted, and the results indicated that the HAP concentrations showed a lognormal distribution. Accordingly, median concentration values were utilized to nominate the HAP concentrations. The median concentrations of individual HAPs monitored in the five areas from 2006 to 2011 are shown in Table 1. Toluene was generally the most abundant HAP for all areas, likely due to the highest emission rate of this pollutant (Na and Kim 2007). As anticipated, BAP (suburban area) displayed the lowest atmospheric concentrations for most 

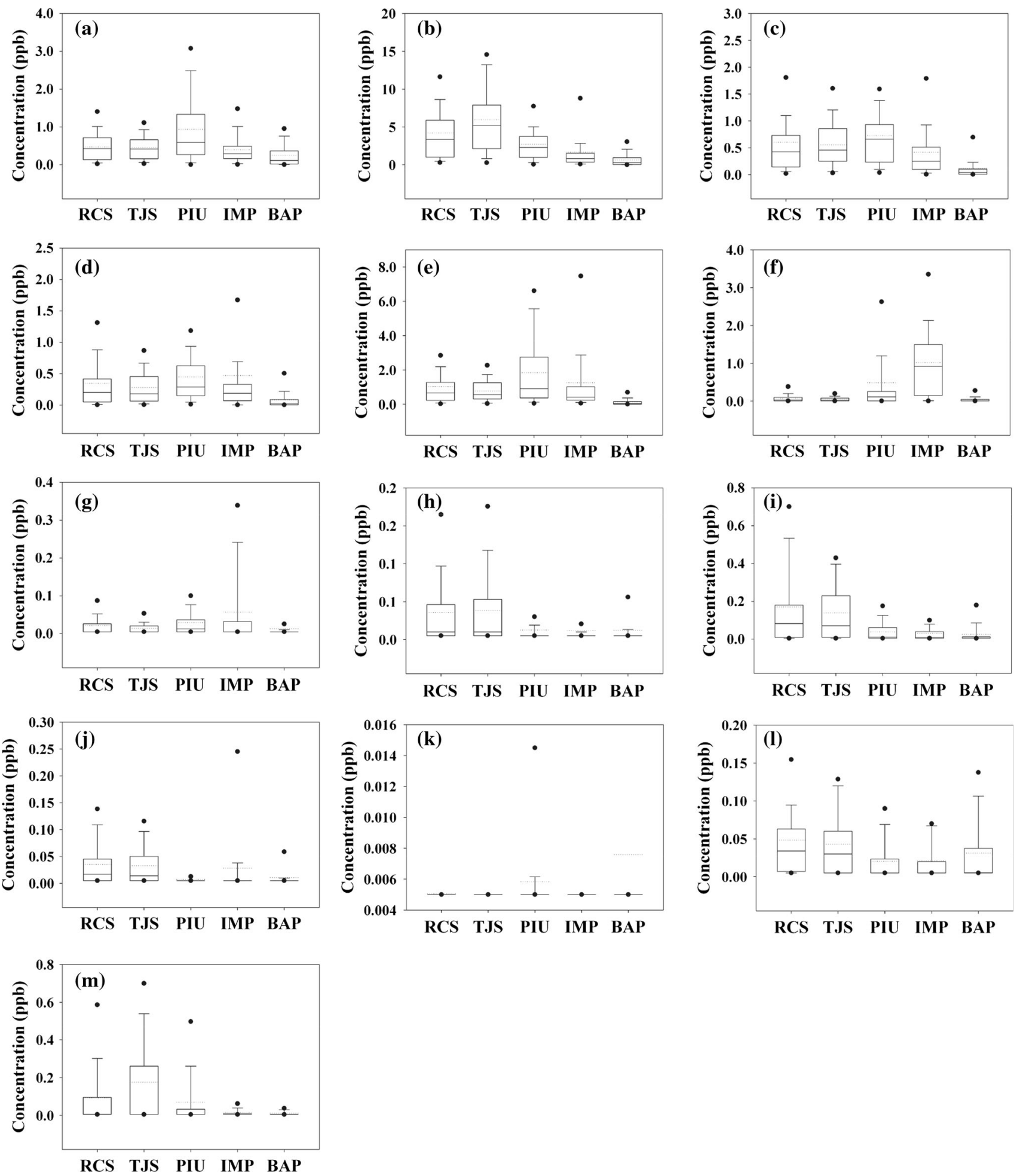

Fig. 2 Box plots of average HAP concentrations ( $\mathrm{ppb}$ ) obtained from five monitoring stations (RCS, TJS, PIU, IMP, and BAP) from 2006 to 2011: a BZ; b TL; $\mathbf{c}$ EB; d OX; e MPX; f ST; $\mathbf{g}$ CF; h MCF; i TCE; j PCE; k 11DCE, I CT; m 13BT. The bottom and top lines represent

the 10th and 90th percentiles, respectively, the bottom and top circles represent the 5th and 95th percentiles, and the dotted line represents the mean value

petroleum refining, oil production, solvent storage, and other handling processes (Axelsson et al. 2010). For these compounds, the RCS and TJS, which showed similar 
Table 1 Median values of average HAP concentrations (ppb) obtained at five monitoring stations from 2006 to 2011

\begin{tabular}{llllll}
\hline HAPs & RCS & TJS & PIU & IMP & BAP \\
\hline BZ & 0.424 & 0.414 & 0.592 & 0.289 & 0.115 \\
TL & 3.345 & 5.210 & 2.281 & 0.823 & 0.281 \\
EB & 0.424 & 0.458 & 0.659 & 0.250 & 0.039 \\
OX & 0.205 & 0.182 & 0.289 & 0.190 & 0.020 \\
MPX & 0.669 & 0.560 & 0.911 & 0.409 & 0.040 \\
ST & 0.030 & 0.024 & 0.114 & 0.020 & 0.005 \\
CF & 0.005 & 0.005 & 0.013 & 0.005 & 0.005 \\
MCF & 0.010 & 0.010 & 0.005 & 0.005 & 0.005 \\
TCE & 0.082 & 0.071 & 0.010 & 0.010 & 0.005 \\
PCE & 0.017 & 0.014 & 0.005 & 0.005 & 0.005 \\
11DCE & 0.005 & 0.005 & 0.005 & 0.005 & 0.005 \\
CT & 0.034 & 0.030 & 0.005 & 0.005 & 0.005 \\
13BT & 0.006 & 0.005 & 0.005 & 0.005 & 0.005 \\
\hline RCS & & & & &
\end{tabular}

$\overline{R C S}$ residential-commercial complex at Seoul, TJS traffic junction area at Seoul, PIU petrochemical industries-concentrated area at Ulsan, IMP iron and metal industries-concentrated area at Pohang, BAP background area at Padolee, Chungnam

concentrations to each other, had the second highest median values, followed by the IMP and BAP. These results were ascribed to higher emissions from motor vehicles at RCS (residential-commercial complex area) and TJS (traffic junction area) in Seoul compared to the IMP (Pohang) and BAP (suburban area) with less populations. The major atmospheric sources of five of the six HAPs (BZ, $\mathrm{EB}, \mathrm{OX}, \mathrm{MPX}$, and ST) were petrochemical handling processes and motor vehicles (Leuchner and Rappenglück 2010). The RCS and TJS showed the highest and second highest toluene concentrations, respectively, as well as higher concentrations of the other four HAPs (MCF, TCE, PCE, and CT) relative to the rest of the survey areas. These differences were likely due to greater solvent use in Seoul, because these chemicals are contained in a variety of solvents, including dry cleaners ( $\mathrm{Na}$ and Kim 2007). CF is also emitted from drinking or waste water treatment plants (Oskouie et al. 2008; Chu et al. 2011). In addition, two HAPs (11DCE and 13BT) showed similar concentrations among the five survey areas.

\section{Long-term temporal variation}

Long-term temporal variations in the ambient concentrations of six HAPs (BZ, TL, EB, OX, MPX, and 13BT), which were selected based on high concentrations or toxicity, were further investigated. Figure 3 shows the annual trends in average concentrations of the six selected HAPs in the five areas from 2006 to 2011. The long-term trends in the annual mean HAP concentrations exhibited unpredictable behavior that varied by area and type of HAP. Specifically, the mean
HAP concentrations observed at three areas (RCS, PIU, and IMP) fluctuated without showing any patterns. Additionally, 13BT did not show any patterns in average concentrations. For example, the average concentrations of 13BT for RCS were $0.007,0.006,0.007,0.008,0.007$, and $0.007 \mathrm{ppb}$ for 2006, 2007, 2008, 2009, 2010, and 2011, respectively. Consequently, the variations in annual HAP concentrations observed in many cases cannot be reasonably explained without further information; therefore, the annual trends obtained from this study are not likely to be useful in determining whether previous HAP control measures applied to the five areas were successful or not. Exceptionally, the mean HAP concentrations for IMP showed an increasing trend from 2006 to 2010, while those for BAP displayed a decreasing trend since 2007. The increasing trend in mean HAP concentrations for IMP was most likely due to the gradual increase in metal production activities, while the decreasing trend for BAP was ascribed to effective control measures implemented at the suburban area. The MPX concentration at sites RCS and TJS gradually increased in the years 2006, 2007, 2008 and then rapidly decreased to very low levels in 2009, 2010, and 2011. The increasing pattern over the former 3-year period was attributed to the gradual increase in traffic emissions due to the increase in the number of motor vehicles, while the increasing pattern over the latter 3-year period was likely due to the enforcement of emission control policy for motor vehicles since 2009.

Figure 4 shows the seasonal trends in the average concentrations of the six selected HAPs for each investigated area. The seasonal concentrations varied with pollutant types as well as by area. Specifically, toluene concentrations, which displayed the most abundant HAP in all areas, were highest for the three areas (RCS, TJS, and PIU) during winter, while they were highest for IMP and BAP during spring and autumn, respectively. According to the Korean Petroleum Institute, the proportion of aromatic constituents in gasoline sold in Korea ranges from 20 to $35 \%$, with benzene accounting for 1.0 to $3.0 \%$, toluene 10 to $20 \%$, ethyl benzene 3 to $5 \%$, and xylenes 6 to $7 \%$. The fuel blends of these constituents varied little with seasons. Since traffic emissions are a primary source of organic HAPs in Korea (Na et al. 2005), the highest concentration of toluene among the target HAPs was attributed to the highest proportion of toluene in gasoline. One possible cause of the higher benzene and toluene concentrations during winter relative to summer could have been the lower combustion efficiency of gasoline, causing higher VOC concentrations in the roadway air due to incomplete combustion. This assertion was supported by Deng et al. (2011), who reported that high tailpipe emissions from motor vehicles are associated with cold ambient temperature. In addition, the highest amount of heating fuel is 
Fig. 3 Annual average concentrations (ppb) and standard errors of six selected HAPs (BZ, TL, EB, OX, MPX, and 13BT) for five areas: a RCS; b TJS; c PIU; d IMP; and $\mathbf{e}$ BAP
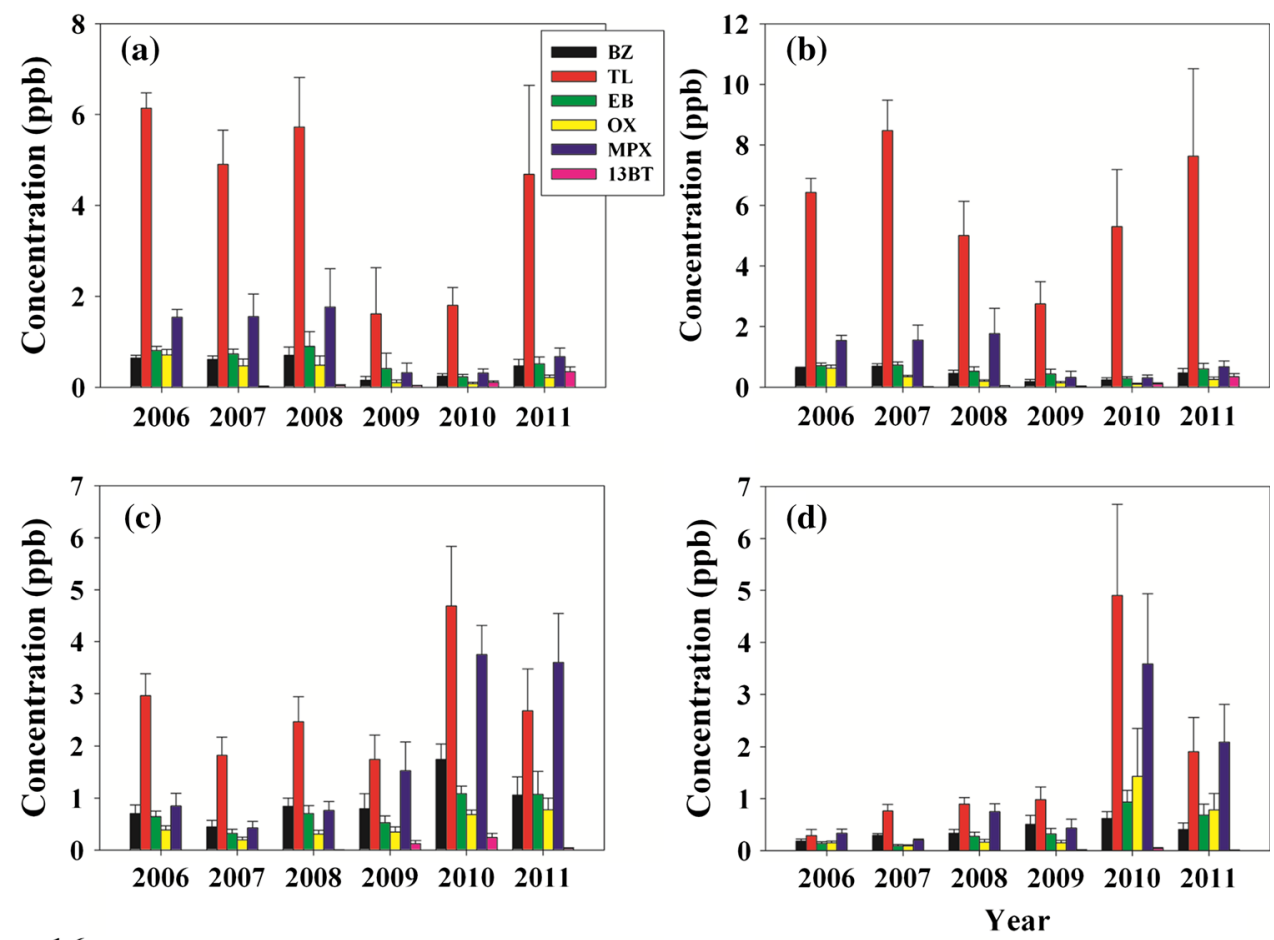

typically consumed in Korean urban areas during winter, which elevates the ambient air pollutant levels in these regions (Lee et al. 2006). Higher atmospheric stability is also generally observed in Korea during winter due to the more frequent occurrence of low inversion heights, which elevate ground-level air pollution (Lee et al. 2008). Moreover, seasonal rain fronts typically occur in Korea during the summer months, which increase the wet deposition of atmospheric toluene ( $\mathrm{Vu}$ et al. 2011). Vehicle evaporation emissions may also be higher during summer than winter due to increased evaporation of gasoline constituents from fuel tanks and engines in summer (Yurdakul et al. 2013). Nevertheless, the higher atmospheric toluene concentration during winter suggests that the winter low combustion efficiency effect would overweigh the summer high evaporation effect on ambient toluene concentrations in RCS, TJS, and PIU. In addition, the other target HAPs exhibited different seasonal variations depending on area. These results were likely a result of seasonal variations in meteorological factors, such as wind speed, humidity, and mixing height, as well as long-range transport of HAPs.

\section{Correlation among selected HAPs}

Table 2 shows the correlation coefficients of the atmospheric HAPs monitored at the five categorical areas from 2006 to 2011. For two monitoring areas (RCS and TJS), six aromatic HAPs (BZ, TL, EB, OX, MPX, and ST) were significantly correlated among themselves. These results were ascribed to high traffics as a common source of the aforementioned compounds at the residential-commercial complex and traffic junction in Seoul, since these pollutants are markers of motor vehicle emissions. Similarly, Parra et al. (2006) found high correlations among all of six HAPs except for ST in northern Spain. However, it is notable that styrene and BTEX compounds in industrial area may show an insignificant correlation, possibility due to ST emissions from industrial activities. Other studies (Na et al. 2005; Nguyen et al. 2009) 
Fig. 4 Seasonal average concentrations (ppb) and standard errors of six selected HAPs (BZ, TL, EB, OX, MPX, and 13BT) for five areas: a RCS; b TJS; c PIU; d IMP; and $\mathbf{e}$ BAP
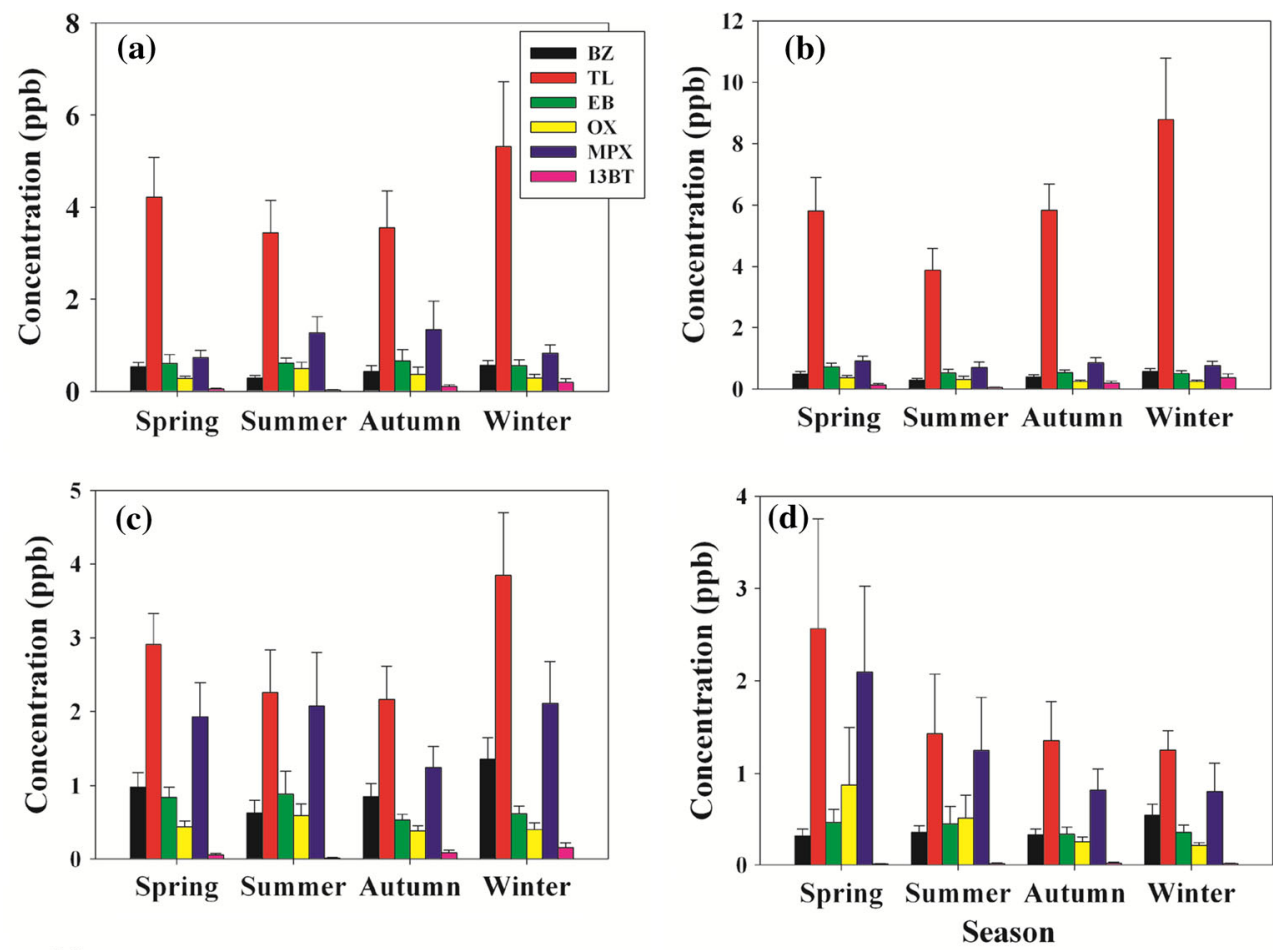

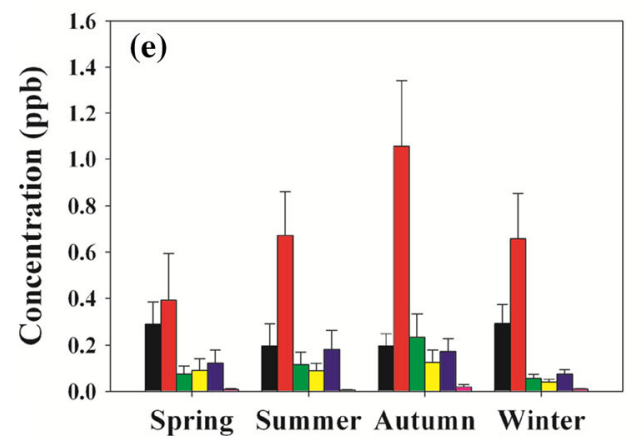

have also revealed significant correlations among aromatic hydrocarbons in Seoul, although the location of HAP monitoring areas differed between this and previous studies. One chlorinated HAP (CF) was also significantly correlated with the six aromatic HAPs, which was attributed to the combined effects of traffic and petrochemical handling processes in the petrochemical industry-concentrated area in Ulsan. However, there was no significant correlation among other chlorinated HAPs, suggesting that their emission sources are not same. At IMP and BAP, certain aromatic HAPs were significantly correlated with each other, suggesting that these areas were at least partially influenced by traffic emissions. Meanwhile, both 13BT and BTEX are important motor vehicle-emission marker and thus, there should be a statistical significant correlation between them. Nevertheless, in the present study there was no significant correlation between BTEX compounds and 13BT. These results are most likely due to low concentrations of 13BT with little variation in the average range of $0.005-0.006 \mathrm{ppb}$ (Table 1).

\section{Relationship of HAP concentrations with meteorological parameters}

The correlation of the concentrations of individual HAPs with three important meteorological parameters (relative humidity, temperature, and wind speed) is shown in Table 3. The meteorological data were obtained from the meteorological offices of each city because area-specific meteorological data were unavailable. In most cases, the three meteorological parameters were not significantly correlated with HAP concentrations, although a few cases revealed a significant correlation. In addition, based on our preliminary study (data not shown), there was no significant correlation between wind direction and VOC concentrations. These results were not consistent with those of previous atmospheric polycyclic aromatic hydrocarbon studies (Karar and Gupta 2006; Tham et al. 2008). Strong wind speed could exert a dilution effect on atmospheric concentrations (Karar and Gupta 2006), while high temperature could increase the photochemical reactions of 


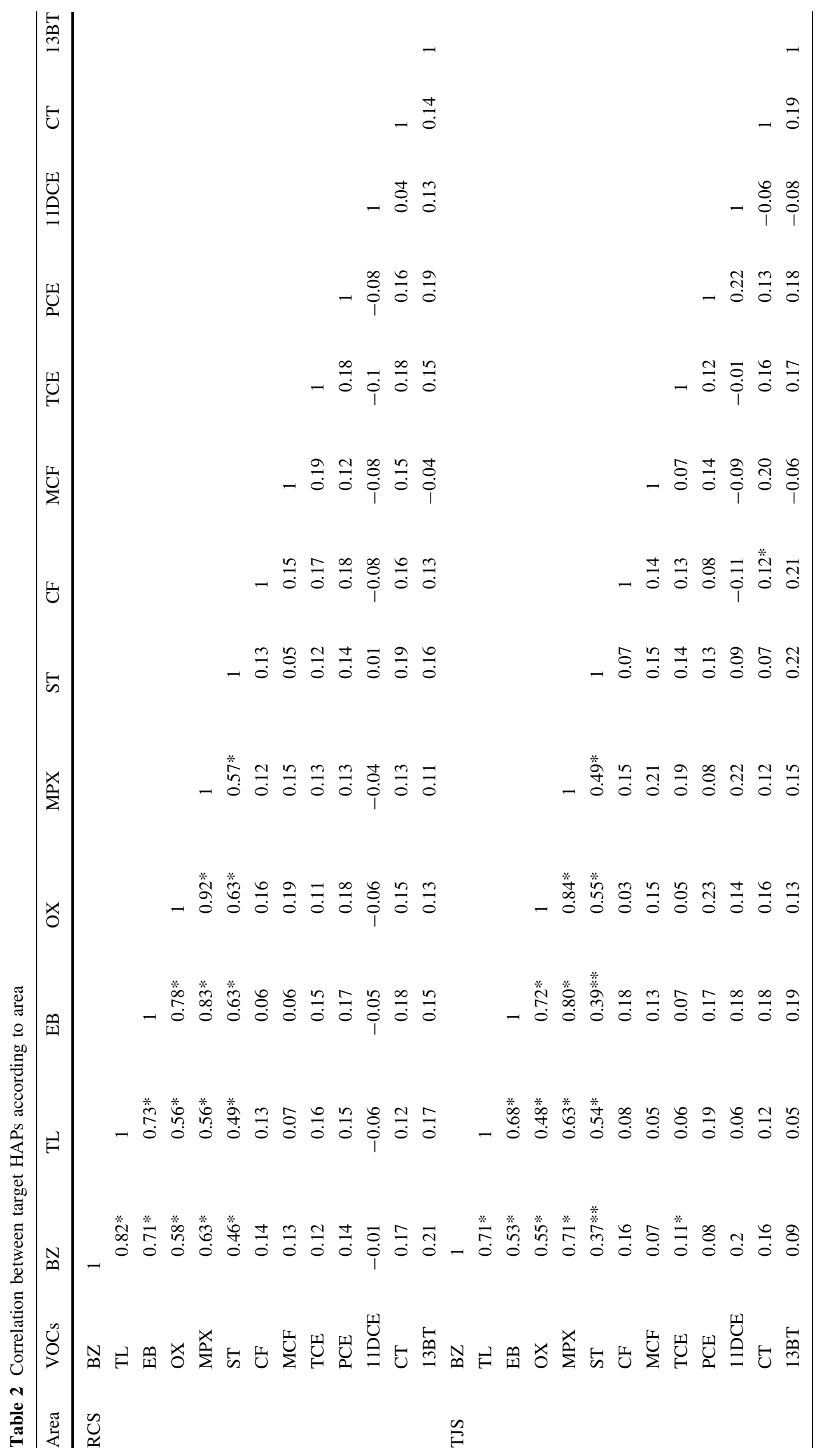




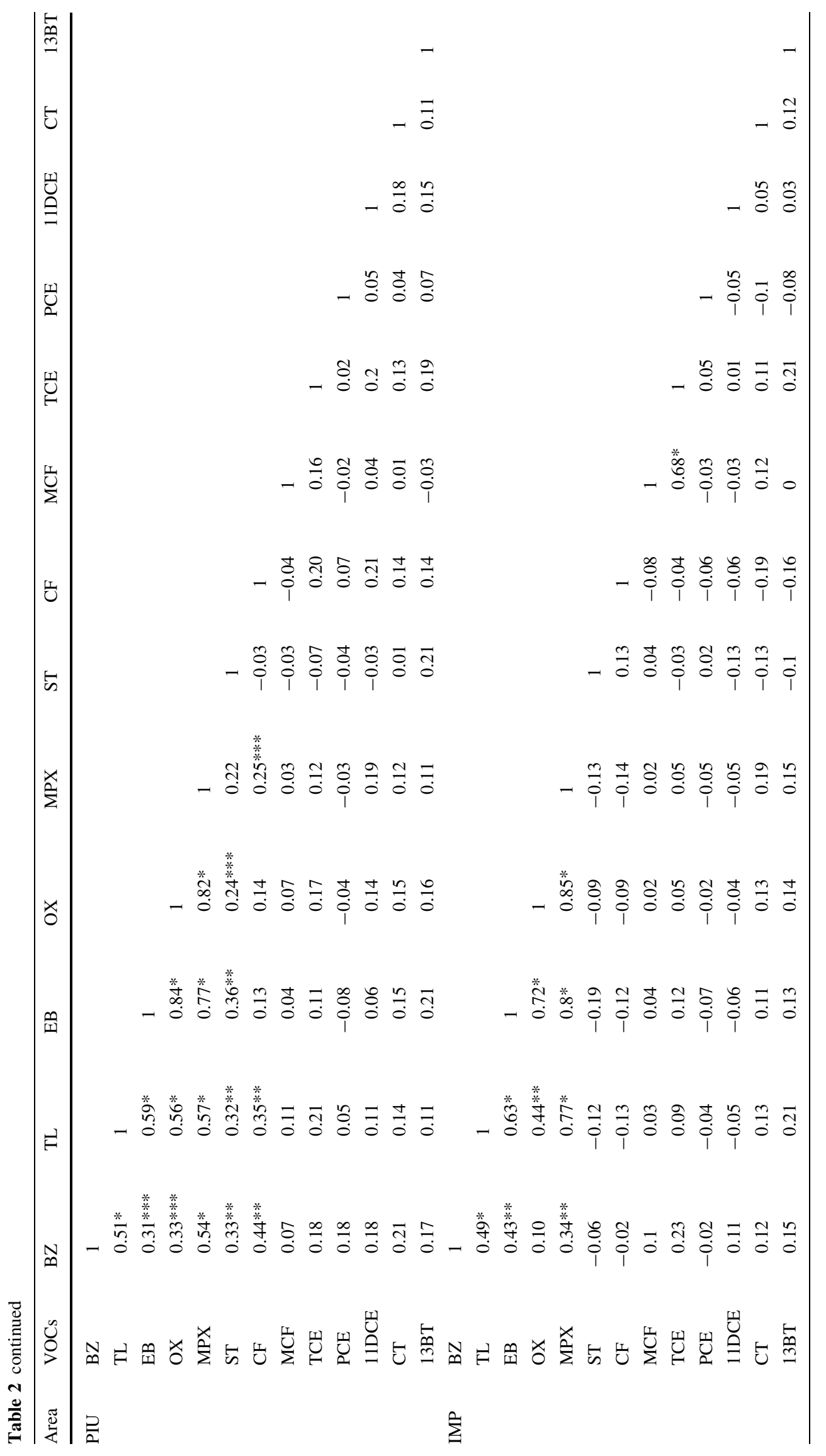




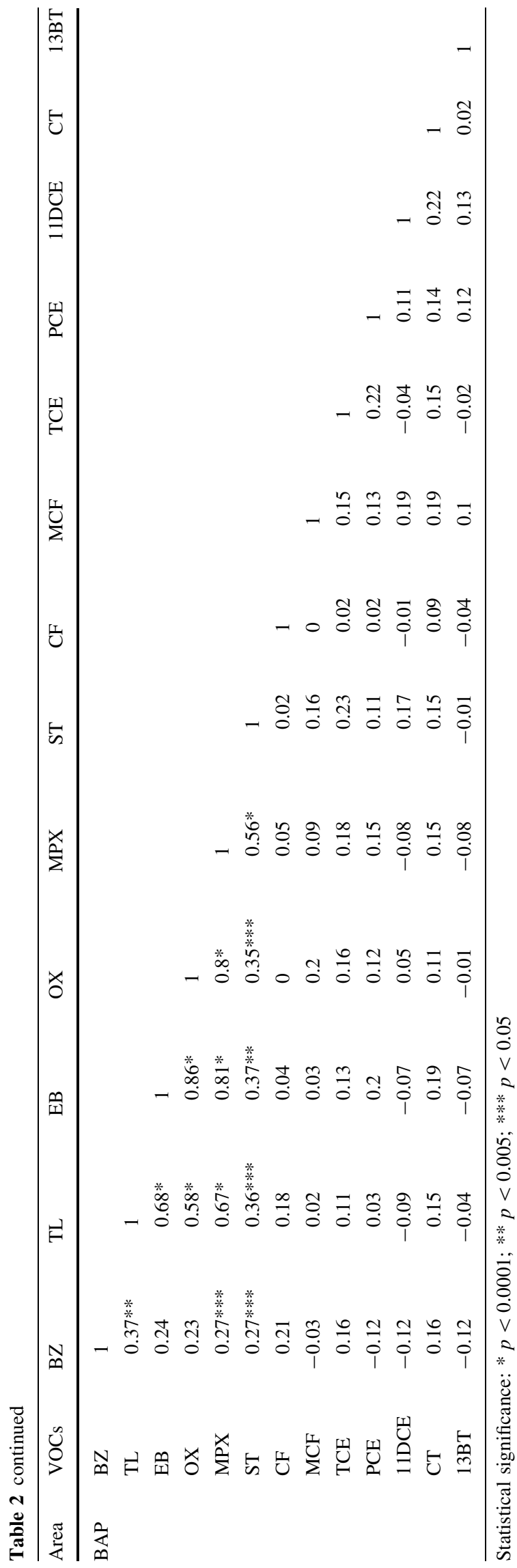

HAPs, thereby reducing HAP concentrations (Stroud et al. 2008). In contrast to the present study, Parra et al. (2006) reported a positive correlation between relative humidity and the concentrations of certain aromatic HAPs. The reason for this difference remains unclear; therefore, further studies to address this issue are warranted. Meanwhile, it is noteworthy that, although information on mixing heights is unavailable in the present study, mixing heights can be highly correlated with VOC concentrations (Sangiorgi et al. 2011; Yuan et al. 2013). It is also interesting to note that there was no significant correlation between four aromatic VOCs (BZ, TL, EB, and MPX) and 13BT, which are all markers for vehicle emissions. These results are ascribed to trivial variation in concentrations of $13 \mathrm{BT}$. Meanwhile, it is noted that mixing height may be highly correlated with HAP concentrations. Nevertheless, we could not collect all necessary data because of limited logistics, which is a limitation of this study.

\section{Risk assessment}

Table 4 shows the cancer risks and the hazard quotients (HQs) for non-carcinogenic health effects of the selected HAPs monitored in the five study areas. BZ was the only HAP that exceeded the cancer risk levels of $1 \times 10^{-6}$, and this excess only occurred at RCS, TJS, and PIU, where cancer risk levels of $1.06 \times 10^{-6}, 1.04 \times 10^{-6}$, and $1.48 \times 10^{-6}$, respectively, were observed. In addition, the cancer risk level for IMP was close to $1 \times 10^{-6}$, whereas the cancer risk level for BAP was much lower. BZ exposure has often been associated with adverse genetic effects and increased cancer risks (Snyder 2002; Pyatt and Hays 2010). Chronic exposure to BZ can also cause bone marrow depression, which is characterized by leukocytopenia, thrombocytopenia, granulocytopenia, and pancytopenia (Snyder 2002). In addition, the cancer risk levels associated with 13BT exposure were close to $1 \times 10^{-6}$ in all five areas. Environmental exposure to this pollutant is closely associated with lymphohematopoietic cancers (Divine and Hartman 2001) and leukemia (Delzell et al. 2001) in industrial environments. This pollutant can also cause other non-cancerous health hazards such as adverse reproductive and developmental effects (USEPA 2010). However, no HAPs exhibited HQ levels that exceeded 1 for any areas. It should be noted that these HQ values would be somewhat underestimated because acute REL values were utilized to evaluate chronic toxicities of HAPs. Nevertheless, the results obtained in the present study suggested that HAPs control strategies should be focused on BZ and 13BT to reduce the risk of cancer posed to residents in four (RCS, TJS, PIU, and IMP) of the five study areas. Additionally, the cancer risk levels observed in this study were lower than the results obtained in Portland, OR, USA (Tam and Neumann 2004). In the aforementioned 
Table 3 Pearson correlation of HAP concentrations with meteorological parameters for five areas

\begin{tabular}{|c|c|c|c|c|c|c|c|}
\hline \multirow[t]{2}{*}{ HAPs } & \multirow[t]{2}{*}{ Region } & \multicolumn{2}{|c|}{ Absolute humidity } & \multicolumn{2}{|c|}{ Temperature } & \multicolumn{2}{|c|}{ Wind speed } \\
\hline & & $R^{2}$ & $p$ Value & $R^{2}$ & $p$ Value & $R^{2}$ & $p$ Value \\
\hline \multirow[t]{5}{*}{$\mathrm{BZ}$} & RCS & 0.047 & 0.153 & 0.037 & 0.203 & 0.023 & 0.318 \\
\hline & TJS & 0.078 & 0.056 & 0.061 & 0.096 & 0.001 & 0.873 \\
\hline & $\mathrm{PIU}$ & 0.031 & 0.249 & 0.031 & 0.245 & 0.030 & 0.249 \\
\hline & IMP & 0.069 & 0.086 & 0.146 & 0.010 & 0.000 & 0.988 \\
\hline & BAP & 0.020 & 0.391 & 0.011 & 0.520 & 0.031 & 0.278 \\
\hline \multirow[t]{5}{*}{$\mathrm{TL}$} & $\mathrm{RCS}$ & 0.003 & 0.711 & 0.000 & 0.963 & 0.042 & 0.179 \\
\hline & TJS & 0.000 & 0.970 & 0.011 & 0.488 & 0.026 & 0.284 \\
\hline & PIU & 0.031 & 0.248 & 0.049 & 0.144 & 0.058 & 0.107 \\
\hline & IMP & 0.117 & 0.020 & 0.114 & 0.021 & 0.008 & 0.544 \\
\hline & BAP & 0.037 & 0.240 & 0.046 & 0.189 & 0.042 & 0.202 \\
\hline \multirow[t]{5}{*}{ EB } & $\mathrm{RCS}$ & 0.016 & 0.408 & 0.040 & 0.190 & 0.049 & 0.145 \\
\hline & TJS & 0.066 & 0.082 & 0.102 & 0.029 & 0.022 & 0.321 \\
\hline & PIU & 0.009 & 0.529 & 0.008 & 0.568 & 0.001 & 0.809 \\
\hline & IMP & 0.103 & 0.039 & 0.144 & 0.013 & 0.002 & 0.788 \\
\hline & BAP & 0.030 & 0.303 & 0.038 & 0.246 & 0.052 & 0.159 \\
\hline \multirow[t]{5}{*}{ OX } & RCS & 0.085 & 0.055 & 0.100 & 0.037 & 0.120 & 0.020 \\
\hline & TJS & 0.038 & 0.196 & 0.057 & 0.109 & 0.035 & 0.207 \\
\hline & $\mathrm{PIU}$ & 0.007 & 0.601 & 0.013 & 0.457 & 0.000 & 0.993 \\
\hline & IMP & 0.085 & 0.067 & 0.093 & 0.056 & 0.000 & 0.986 \\
\hline & BAP & 0.052 & 0.194 & 0.072 & 0.124 & 0.041 & 0.211 \\
\hline \multirow[t]{5}{*}{ MPX } & RCS & 0.056 & 0.119 & 0.075 & 0.069 & 0.064 & 0.094 \\
\hline & TJS & 0.009 & 0.524 & 0.038 & 0.187 & 0.039 & 0.186 \\
\hline & $\mathrm{PIU}$ & 0.040 & 0.185 & 0.049 & 0.140 & 0.013 & 0.460 \\
\hline & IMP & 0.132 & 0.013 & 0.131 & 0.013 & 0.011 & 0.483 \\
\hline & BAP & 0.069 & 0.112 & 0.069 & 0.112 & 0.004 & 0.704 \\
\hline \multirow[t]{5}{*}{ ST } & RCS & 0.063 & 0.096 & 0.043 & 0.174 & 0.120 & 0.020 \\
\hline & TJS & 0.008 & 0.543 & 0.003 & 0.716 & 0.063 & 0.096 \\
\hline & $\mathrm{PIU}$ & 0.001 & 0.859 & 0.002 & 0.763 & 0.004 & 0.695 \\
\hline & IMP & 0.133 & 0.013 & 0.088 & 0.046 & 0.072 & 0.071 \\
\hline & BAP & 0.001 & 0.836 & 0.000 & 0.943 & 0.002 & 0.800 \\
\hline \multirow[t]{5}{*}{$\mathrm{CF}$} & RCS & 0.003 & 0.733 & 0.004 & 0.678 & 0.000 & 0.968 \\
\hline & TJS & 0.019 & 0.354 & 0.008 & 0.547 & 0.001 & 0.807 \\
\hline & PIU & 0.137 & 0.011 & 0.218 & 0.001 & 0.069 & 0.078 \\
\hline & IMP & 0.021 & 0.335 & 0.033 & 0.228 & 0.044 & 0.160 \\
\hline & BAP & 0.016 & 0.437 & 0.016 & 0.437 & 0.021 & 0.373 \\
\hline \multirow[t]{5}{*}{$\mathrm{MCF}$} & RCS & 0.006 & 0.608 & 0.012 & 0.466 & 0.009 & 0.536 \\
\hline & TJS & 0.027 & 0.274 & 0.020 & 0.342 & 0.012 & 0.477 \\
\hline & $\mathrm{PIU}$ & 0.003 & 0.728 & 0.001 & 0.803 & 0.042 & 0.173 \\
\hline & IMP & 0.074 & 0.067 & 0.049 & 0.138 & 0.016 & 0.407 \\
\hline & BAP & 0.064 & 0.117 & 0.040 & 0.216 & 0.033 & 0.260 \\
\hline \multirow[t]{5}{*}{ TCE } & RCS & 0.014 & 0.431 & 0.001 & 0.847 & 0.027 & 0.284 \\
\hline & TJS & 0.001 & 0.801 & 0.002 & 0.764 & 0.003 & 0.702 \\
\hline & PIU & 0.001 & 0.842 & 0.001 & 0.846 & 0.002 & 0.773 \\
\hline & IMP & 0.028 & 0.265 & 0.021 & 0.337 & 0.001 & 0.828 \\
\hline & BAP & 0.060 & 0.129 & 0.045 & 0.189 & 0.042 & 0.202 \\
\hline
\end{tabular}


Table 3 continued

\begin{tabular}{|c|c|c|c|c|c|c|c|}
\hline \multirow[t]{2}{*}{ HAPs } & \multirow[t]{2}{*}{ Region } & \multicolumn{2}{|c|}{ Absolute humidity } & \multicolumn{2}{|c|}{ Temperature } & \multicolumn{2}{|c|}{ Wind speed } \\
\hline & & $R^{2}$ & $p$ Value & $R^{2}$ & $p$ Value & $R^{2}$ & $p$ Value \\
\hline \multirow[t]{5}{*}{ PCE } & RCS & 0.002 & 0.748 & 0.014 & 0.435 & 0.002 & 0.795 \\
\hline & TJS & 0.048 & 0.141 & 0.038 & 0.188 & 0.004 & 0.694 \\
\hline & PIU & 0.061 & 0.099 & 0.017 & 0.383 & 0.000 & 0.935 \\
\hline & IMP & 0.171 & 0.004 & 0.125 & 0.016 & 0.027 & 0.277 \\
\hline & BAP & 0.091 & 0.059 & 0.068 & 0.103 & 0.014 & 0.466 \\
\hline \multirow[t]{5}{*}{ 11DCE } & RCS & 0.001 & 0.842 & 0.001 & 0.861 & 0.000 & 0.956 \\
\hline & TJS & 0.001 & 0.807 & 0.000 & 0.952 & 0.002 & 0.753 \\
\hline & PIU & 0.000 & 0.935 & 0.004 & 0.663 & 0.062 & 0.096 \\
\hline & IMP & 0.016 & 0.406 & 0.025 & 0.295 & 0.005 & 0.644 \\
\hline & BAP & 0.023 & 0.354 & 0.033 & 0.264 & 0.044 & 0.192 \\
\hline \multirow[t]{5}{*}{$\mathrm{CT}$} & RCS & 0.000 & 0.901 & 0.004 & 0.675 & 0.052 & 0.134 \\
\hline & TJS & 0.003 & 0.713 & 0.000 & 0.888 & 0.028 & 0.274 \\
\hline & PIU & 0.008 & 0.555 & 0.016 & 0.396 & 0.070 & 0.077 \\
\hline & IMP & 0.009 & 0.540 & 0.002 & 0.786 & 0.007 & 0.581 \\
\hline & BAP & 0.006 & 0.622 & 0.000 & 0.947 & 0.006 & 0.639 \\
\hline \multirow[t]{5}{*}{$13 \mathrm{BT}$} & RCS & 0.005 & 0.639 & 0.001 & 0.824 & 0.011 & 0.498 \\
\hline & TJS & 0.043 & 0.163 & 0.037 & 0.193 & 0.000 & 0.961 \\
\hline & PIU & 0.026 & 0.287 & 0.033 & 0.229 & 0.079 & 0.059 \\
\hline & IMP & 0.066 & 0.084 & 0.081 & 0.055 & 0.002 & 0.754 \\
\hline & BAP & 0.000 & 0.978 & 0.000 & 0.986 & 0.056 & 0.140 \\
\hline
\end{tabular}

Table 4 Unit risks and median cancer risks $\left(\mathrm{R}_{\mathrm{c}} \mathrm{s}\right)$ for carcinogenic effect and RfC (or REL) and median hazard quotients (HQs) for noncarcinogenic health effects of the target HAPs for five areas

\begin{tabular}{|c|c|c|c|c|}
\hline HAP & Unit risk $(\text { per } \mathrm{ppb})^{\mathrm{a}}$ & $\mathrm{R}_{\mathrm{c}} \mathrm{s}, \mathrm{RCS} / \mathrm{TJS} / \mathrm{PIU} / \mathrm{IMP} / \mathrm{BAP} \times 10^{6}$ & RfC or REL (ppb) & HQs, RCS/TJS/PIU/IMP/BAP \\
\hline BZ & $2.5 \times 10^{-6}$ & $1.06 / 1.04 / 1.48 / 0.72 / 0.29$ & $9^{\mathrm{b}}$ & $0.05 / 0.05 / 0.07 / 0.03 / 0.01$ \\
\hline $\mathrm{TL}$ & NA & NA & $80^{\mathrm{c}}$ & $0.04 / 0.07 / 0.03 / 0.01 /<0.01$ \\
\hline EB & NA & NA & $231^{\mathrm{b}}$ & $<0.01 /<0.01 /<0.01<0.01<0.01$ \\
\hline $\mathrm{OX}$ & NA & NA & $23^{\mathrm{b}}$ & $0.01 / 0.01 / 0.01 / 0.01 /<0.01$ \\
\hline MPX & NA & NA & $23^{\mathrm{b}}$ & $0.03 / 0.02 / 0.04 / 0.02 /<0.01$ \\
\hline ST & NA & NA & $212^{\mathrm{c}}$ & $<0.01 /<0.01 /<0.01<0.01<0.01$ \\
\hline $\mathrm{CF}$ & $4.7 \times 10^{-6}$ & $0.02 / 0.02 / 0.06 / / 0 / 02 / 0.02$ & $69^{c}$ & $<0.01 /<0.01 /<0.01<0.01<0.01$ \\
\hline $\mathrm{MCF}$ & NA & NA & $184^{\mathrm{c}}$ & $<0.01 /<0.01 /<0.01<0.01<0.01$ \\
\hline TCE & $0.4 \times 10^{-6}$ & $0.03 / 0.03 /<0.01 /<0.01 /<0.01$ & $112^{\mathrm{c}}$ & $<0.01 /<0.01 /<0.01<0.01<0.01$ \\
\hline PCE & $0.9 \times 10^{-6}$ & $0.02 / 0.01 /<0.01 /<0.01 /<0.01$ & $5^{\mathrm{c}}$ & $<0.01 /<0.01 /<0.01<0.01<0.01$ \\
\hline 11DCE & NA & NA & NA & NA \\
\hline CT & $7.1 \times 10^{-6}$ & $0.26 / 0.21 / 0.04 / 0.04 / 0.04$ & $6^{\mathrm{c}}$ & $0.01 / 0.01 /<0.01<0.01<0.01$ \\
\hline $13 \mathrm{BT}$ & $127 \times 10^{-6}$ & $0.76 / 0.64 / 0.64 / 0.64 / 0.64$ & $1^{\mathrm{b}}$ & $0.01 / 0.01 / 0.01 / 0.01 / 0.01$ \\
\hline
\end{tabular}

$N A$ not available; $\mathrm{R}_{\mathrm{c}} \mathrm{s}$ or HQs RCS/TJS/PIU/IMP/BAP represent $\mathrm{R}_{\mathrm{c}}$ or HQ values estimated for five areas (RCS, TJS, PIU, IMP, and BAP), respectively

${ }^{a}$ Unit risk is the upper limit increased lifetime cancer risk of an individual who is exposed for a lifetime to 1 ppb in air (USEPA 2010)

${ }^{b} \mathrm{RfC}$ is the inhalation reference concentration that is likely to be without an appreciable risk of deleterious effects during a lifetime (USEPA 2010)

c REL is the recommended exposure limit at which no adverse health effects are anticipated for a specified exposure period (USEPA 2010)

study, the nominal cancer risk levels of BZ, CF, TCE, PCE, $\mathrm{CT}$, and 13BT were $15.3 \times 10^{-6}, 5.71 \times 10^{-6}$, $4.41 \times 10^{-6}, 4.61 \times 10^{-6}, 42.7 \times 10^{-6}$, and $38.3 \times 10^{-6}$, respectively. However, the cancer risk levels in Portland may have changed owing to implementation of different HAPs control measures since the study was conducted. 


\section{Conclusion}

In this study, the spatial and long-term temporal characteristics of selected organic HAPs and the health risks associated with inhalation exposure to HAPs in five different areas over a recent 6-year period were investigated. The highest concentrations for six of 13 HAPs were observed in a petrochemical industries-concentrated area. For these compounds, residential-commercial complex and traffic junction areas, which showed similar concentrations to each other, had the second highest median values, followed by an iron and metal industries-concentrated area. As anticipated, the background area displayed the lowest atmospheric concentrations for most HAPs. However, the temporal trends in HAP concentrations exhibited unpredictable behavior that depended on both the area and the type of HAPs. Considering the annual increase in the number of motor vehicles and industrial activities, a steady increase in the annual HAP concentrations was expected. However, the fluctuated temporal trend in HAP concentrations indicates that there was no steady HAP concentration increase, likely due to the HAP emission control measures taken in Korea. Meteorological parameters (relative humidity, temperature, and wind speed) did not reveal any significant correlations with HAP concentrations. Additionally, BZ was the only HAP that exceeded the cancer risk levels of $1 \times 10^{-6}$, and this excess was only observed in three areas. The cancer risk levels associated with $13 \mathrm{BT}$ exposure were also close to $1 \times 10^{-6}$ for all five areas. Overall, the results of this study suggest that HAPs control strategies should focus on BZ and 13BT to effectively reduce the risk of cancer posed to residents in urban areas.

Acknowledgments This work was supported by the National Research Foundation of Korea (NRF) grant funded by the Korean government (MEST) (No. 2011-0027916) and GCRC-SOP (No. 2011-0030013). We also appreciate the reviewers for their thoughtful and valuable suggestions.

\section{References}

Axelsson G, Barregard L, Holmberg E, Sallsten G (2010) Cancer incidence in a petrochemical industry area in Sweden. Sci Total Environ 408:4482-4487

Badol C, Locoge N, Léonardis T, Galloo J-C (2008) Using a sourcereceptor approach to characterize VOC behaviour in a French urban area influenced by industrial emissions Part I: study area description, data set acquisition and qualitative data analysis of the data set. Sci Total Environ 389:441-452

Barregard L, Holmberg E, Sallsten G (2009) Leukaemia incidence in people living close to an oil refinery. Environ Res 109:985-990

Blanchard CL, Hidy GM, Tanenbaum S, Rasmussen R, Watkins R, Edgerton E (2010) NMOC, ozone, and organic aerosols in the southeastern United States, 1999-2007: 1. Spatial and temporal variations of NMOC concentrations and composition in Atlanta, Georgia. Atmos Environ 44:4827-4839

Carter WPL, Seinfeld JH (2012) Winter ozone formation and VOC incremental reactivities in the Upper Green River Basin of Wyoming. Atmos Environ 50:255-266

Chu W, Gao N, Deng Y, Templeton MR, Yin D (2011) Impacts of drinking water pretreatments on the formation of nitrogenous disinfection by-products. Bioresour Technol 102:11161-11166

Delzell E, Macaluso M, Sathiakumar N, Matthews R (2001) Leukemia and exposure to 1,3-butadiene, styrene and dimethyldithiocarbamate among workers in the synthetic rubber industry. Chem Biol Interact 135-136:515-534

Deng Y, Peng P, Ren M, Song J, Huang W (2011) The winter effect on formation of PCDD/Fs in Guangzhou by vehicles: a tunnel study. Atmos Environ 45:2541-2548

Divine BJ, Hartman CM (2001) A cohort mortality study among workers at a 1,3 butadiene facility. Chem Biol Interact 135-136:535-553

Hoque RR, Khillare PS, Agarwal T, Shridhar V, Balachandran S (2008) Spatial and temporal variation of BTEX in the urban atmosphere of Delhi, India. Sci Total Environ 392:30-40

Karar K, Gupta AK (2006) Seasonal variations and chemical characterization of ambient $\mathrm{PM}_{10}$ at residential and industrial sites of an urban area of Kolkata (Calcutta), India. Atmos Res $81: 36-53$

Khoder MI (2007) Ambient levels of volatile organic compounds in the atmosphere of Greater Cairo. Atmos Environ 41:554-566

KME (Korean Ministry of Environment) (2008) Annual Report of Ambient Air Quality in Korea, KME

Lee JY, Kim YP, Kang C-H, Ghim YS (2006) Seasonal trend of particulate PAHs at Gosan, a background site in Korea between 2001 and 2002 and major factors affecting their levels. Atmos Res 82:680-687

Lee HW, Choi H-J, Lee S-H, Kim Y-K, Jung W-S (2008) The impact of topography and urban building parameterization on the photochemical ozone concentration of Seoul, Korea. Atmos Environ 42:4232-4246

Leuchner M, Rappenglück B (2010) VOC source-receptor relationships in Houston during TexAQS-II. Atmos Environ 44:4056-4067

McCarthy MC, O'Brien TE, Charrier JG, Hather HR (2009) Characterization of the chronic risks and hazard of hazardous air pollutants in the United States using ambient monitoring data. Environ Health Perspect 112:589-598

Na K, Kim YP (2007) Chemical mass balance receptor model applied to ambient $\mathrm{C}_{2}-\mathrm{C}_{9}$ VOC concentration in Seoul, Korea: effect of chemical reaction losses. Atmos Environ 41:6715-6728

Na K, Moon K-C, Kim YP (2005) Source contribution to aromatic VOC concentration and ozone formation potential in the atmosphere of Seoul. Atmos Environ 39:5517-5524

Nguyen HT, Kim K-H, Kim M-Y (2009) Volatile organic compounds at an urban monitoring station in Korea. J Hazard Mater 161:163-174

Oskouie AK, Lordi DT, Granato TC, Kollias L (2008) Plant-specific correlations to predict the total VOC emissions from wastewater treatment plants. Atmos Environ 42:4530-4539

Parra MA, González L, Elustondo D, Garrigó J, Bermejo R, Santamaría JM (2006) Spatial and temporal trends of volatile organic compounds (VOC) in a rural area of northern Spain. Sci Total Environ 370:157-167

Pyatt D, Hays S (2010) A review of the potential association between childhood leukemia and benzene. Chem Biol Interact 184:151-164

Sangiorgi G, Ferrero L, Perrone MG, Bolzacchini E, Duane M, Larsen BR (2011) Vertical distribution of hydrocarbons in the low troposphere below and above the mixing height: tethered balloon measurements in Milan, Italy. Environ Pollut 159:3545-3552 
Shin DC, Yang J (2010) Risk based approach for managing toxic VOCs in the air of Seoul. In: Proceeding of the 50th Meeting of Korean Society for Atmospheric Environment. Incheon, Korea, 13-May, pp 73

Snyder R (2002) Benzene and leukaemia. Crit Rev Toxicol 32:155-210 Stroud CA, Morneau G, Makar PA, Moran MD, Gong W, Pabla B, Zhang J, Bouchet VS, Fox D, Venkatesh S, Wang D, Dann T (2008) OH-reactivity of volatile organic compounds at urban and rural sites across Canada: evaluation of air quality model predictions using speciated VOC measurements. Atmos Environ 42:7746-7756

Su F-C, Mukherjee B, Batterman S (2013) Determinants of personal, indoor and outdoor VOC concentrations: an analysis of the RIOPA data. Environ Res 126:192-203

Tam BN, Neumann CM (2004) A human health assessment of hazardous air pollutants in Portland, OP. J Environ Manage 73:131-145

Tham YWF, Takeda K, Sakugawa H (2008) Polycyclic aromatic hydrocarbons (PAHs) associated with atmospheric particles in Higashi Hiroshima, Japan: influence of meteorological conditions and seasonal variations. Atmos Res 88:224-233
Touma JS, Cox WM, Tikvart JA (2006) Spatial and temporal variability of ambient air toxics data. J Air Waste Manage Assoc 56:1716-1725

USEPA (U.S. Environmental Protection Agency) (2010) Integrated Risk Information System. http://www.epa.gov/iris. Accessed 20 December 2010

Vu V-T, Lee B-K, Kim J-T, Lee C-H, Kim I-H (2011) Assessment of carcinogenic risk due to inhalation of polycyclic aromatic hydrocarbons in $\mathrm{PM}_{10}$ from an industrial city: a Korean casestudy. J Hazard Mater 189:349-356

Yoo S-H, Kwak S-J, Lee J-S (2008) Using a choice experiment to measure the environmental costs of air pollution impacts in Seoul. J Environ Manage 86:308-318

Yuan Z, Zhong L, Lau AKH, Yu JZ, Louie PKK (2013) Volatile organic compounds in the Pearl River Delta: identification of source regions and recommendations for emission-oriented monitoring strategies. Atmos Environ 76:162-172

Yurdakul S, Civan M, Tuncel G (2013) Volatile organic compounds in suburban Ankara atmosphere, Turkey: sources and variability. Atmos Res 120-121:298-311 